\title{
Erken Bizans Döneminde Doğu Sınırında Kentleşme Politikası: Martyropolis
}

\section{Martyropolis: Urbanization Policy at the Eastern Border During the Early Byzatine Period}

\author{
Amine $\mathrm{Kaya}^{1}$ (D)
}

*Bu çalışma "Tarihsel Süreç Içerisinde Silvan (Meyyafarikin) Şehrinin Gelişimi" başlıkı Yüksek lisans tezinden türetilmiștir.

'Sorumlu yazar/Corresponding author: Amine Kaya (Doktora Öğrencisi), Mimar Sinan Güzel Sanatlar Üniversitesi, Sanat Tarihi Bölümü, Istanbul, Türkiye

E-posta: fatmaamine.kaya@gmail.com ORCID: 0000-0002-3648-5615

Başvuru/Submitted: 14.02 .2020 Revizyon Talebi/Revision Requested: 11.04.2020

Son Revizyon/Last Revision Received: 15.04.2020

Kabul/Accepted: 17.04.2020

Online Yayın/Published Online: 30.06 .2020

Atıf/Citation: Kaya, Amine, "Erken Bizans Döneminde Doğu Sınııında Kentleşme Politikası: Martyropolis". Sanat Tarihi Yıllığı Journal of Art History 29 (2020), 129-144. https://doi.org/10.26650/sty.2020.007

\section{Öz}

Erken Hıristiyanlık -Bizans döneminde, 4. yüzyılın sonu- 5. yüzyılın başında, Bizans ve Sasani devletlerinin doğu sınır hattında yer alan Martyropolis kenti, din adamı Marusa b. Lyuta tarafından kurulmuştur. Günümüzde ise Diyarbakır'a bağlı Silvan ilçesi olarak konumlanmaktadır. Martyropolis kentinin kuruluş öyküsü Ortaçağ'da, Bizans dönemi kent oluşumlarında sıkça karşılaşılan bir olgu üzerine temellendirilmiştir. Bu doğrultuda kente kutsallık atfetmek adına İran, Mezopotamya ve Asuri şehirlerinde öldürülen Hıristiyan azizlerin kemikleri toplanarak kentte inşa edilen ilk dini yapılara yerleştirilmiştir. Buna binaen kente "Şehitler Şehri" anlamına gelen "Martyropolis" adı verilmiştir. Kentsel yerleşim düzenin ilk çekirdeği, kilise ve kale-burç yapıları etrafında yapılandırılmıştır. Bizans İmparatorları; I. Constantinus ( 273-337) ) I. Anastasios ( 491-518) ve I. lustinianos ( 527-565) döneminde şehirleşme süreci hızlanmıştır.

Anahtar kelimeler: Silvan, Martyropolis Kenti, Bizans Devleti, Kentleşme, Silvan Kalesi

\section{ABSTRACT}

The city of Martyropolis, located on the eastern border line of the Byzantine and Sassanid states in the early Christian -Byzantine period, late 4th century -early 5 th century, was founded by the cleric Marusa b. Lyuta. Today, it is located as Silvan district of Diyarbakır. The story of the establishment of the city of Martyropolis was based on a phenomenon frequently encountered in the city formations of the Byzantine period in the Middle Ages. Accordingly, in order to attribute holiness to the city, the bones of the Christian saints killed in the cities of Iran, Mesopotamia and Assyria were collected and placed in the first religious buildings built in the city. Based on this, the city was called "Martyropolis", which means the "City of Martyrs". The first core of the city settlement is organized around the church and the castle-horoscope structures. Byzantine Emperors; Urbanization process has accelerated in the period of Constantinus I (273-337), Anastasios I (491-518) and I. lustinianos (527-565).

Keywords: Silvan, Martyropolis City, Byzantine State, Urbanization, Silvan Castle 


\section{Martyropolis Kentinin Kuruluşu}

Tarihsel süreç içerisinde Martyropolis kentinin kuruluşu farklı içeriklere sahip aktarımlarla kaydedilmiş, şehrin ortaya çıkma süreciyle ilgili olarak birçok görüş ileri sürülmüş̧ür. Özellikle kentin kuruluş tarihi ve Martyropolis'in antik bir kentin kalıntıları üzerine inşa edilip edilmediği gibi konular etrafında tartışmalar yapılmaktadır. ${ }^{1} \mathrm{Bu}$ durum kentin kuruluşunun farklı dönemlere tarihlendirilmesine neden olmuştur. Yakın zamanda birçok araştırmacı şehrin tarihi ile ilgilenmiş ve bu bağlamda çeşitli görüşler sunmuşlardır.

Şehrin kuruluşunun milattan öncesine tarihlendiğini ileri süren araştırmacılar J. G. Taylor, ${ }^{2}$ Helmuth Von Moltke ${ }^{3}$ ve Lehmann Haupt ${ }^{4}$ gibi isimler olmuştur. Bahsi geçen yazarların ileri sürdükleri görüş, Martyropolis (Meyyafarikin) şehrinin kurulduğu yerde milattan önce antik bir kentin var olduğu ve Martyropolis'in bu kalıntılar üzerinde kurulduğu yönündedir. Örneğin, J. G. Taylor'un 1865 tarihli “Travels in Kurdistan" adlı çalışmasında Martyropolis' in kuruluşu hakkında yaptığı değerlendirmelerde, şehrin kuruluşunu Süryâni geleneğinde yer alan hikâyeden daha farklı bir kuruluş öyküsü ile anlatmaktadır. Bu anlatımın özü şehrin antik kökenlerine işaret etmektedir. ${ }^{5}$

Taylor, Güneydoğu Anadolu bölgesini gezdiği sırada halen yerliler arasında bilinen bir söylenceden bahsetmektedir. Bilinen bu hikâyeye göre, Martyropolis/Meyyafarikin, Armenia Kralı Tigran'ın kız kardeşi Nouphar tarafından kurulduğu, kentin de Nouphar isminin bir uzantısı olan Nouphargerd adıyla anıldığı aktarmaktadır. Daha sonra Taylor kentin kuruluşu ile ilgili olarak;

Nouphargerd antik kentin harabeleri Marusa tarafindan 5. yüzyılın başında restore edilerek Martyropolis kentinin kurulmuş olduğunu ifade etmektedir. ${ }^{6}$

Aynı türden bir yaklaşımı benimseyen Lehmann Haupt da buna benzer bir tez ileri sürmektedir. Haupt tezini, 1898/1899 yıllarında W. Belck ile birlikte bölgeye yaptığı ziyaretinde gördügünü söylediği, Silvan'ın (Martyropolis) kuzey sur duvarları üzerinde yer alan, Kral Tigranes'in valisi Pap'a ait ${ }^{7}$ olduğunu düşündüğü Yunanca kitabelere dayandırmaktadır. Yazara

1 J. G. Taylor, Travels in Kurdistan, with Notices of the Sources of the Eastern and Western Tigris, and Ancient Ruins in Their Neighbourhood, Journal of the Royal Geographical Society of London, vol. 35, 1865, s. 23-24; Carl Friedrich Lehmann-Haupt, Armenien Einst Und Jetzt, C. I, George Olms Verlag (Tipk1 Basımı), Berlin, 1988, s. 381-418; Muzafer Demir, “Antik Kaynaklar Işığında Tikranokerta Şehrinin Lokasyonu Meselesi”, Uluslararası, Batman ve Çevresi Tarihi ve Kültürü Sempozyumu, 2008, s. 172-182; Mehmet Tezcan, “Tigranakerta ile Silvan/ Mayperkat'ın Birleştirilmesi ve Silvan'nın Durumu”, Mardin Artukulu Üniversitesi Yayınları, 2008, s. 33; Ronald, 1981, 61-70; Sinclair, 1996, s. 95-97.

2 Taylor, a.g.e., s. 24

3 Helmuth Von Moltke, Türkiye'deki Durum ve Olaylar Üzerine Mektuplar, Çev. Hayrullah Örs, Türk Tarih Kurumu, Ankara, 1960, s. 224.

4 Haupt, a.g.e., s. 381-85.

5 Taylor, a.g.e., s. 23-25.

6 A.e., s. 24.

7 Haupt, a.g.e., s. 411-12; Şevket Beysanoğlu, Anıtları ve Kitâbeleri ile Diyarbakır Tarihi, Cilt, I, Diyarbakır Belediyesi, Ankara, 1996, s. 27. 
göre, Martyropolis, M. Ö. 1. yüzyılda II. Tigranes tarafından kurulan krallığın başkenti olan Tigran Şehri "Tigranokerta" üzerinde kurulmuş olmalıdır. ${ }^{8}$

Haupt, yine “Armenien Einst Und Jetzt” adlı eserinde, Martyropolis'in Tikranokerta olduğuna dair veri niteliği taşıdığını öne sürdüğü yazıtların içerikleri hakkında yaptığı değerlendirmeleri şu şekilde olmaktadır;

Yazıtlarda, bir kralın yönettiği topluma hitap ettiği anlaşılmaktadır. Kral, kendi toplumundan “köleleri” olarak bahseder. Bu ifadenin Doğu ülkesinden bir kralın benimsediği bir yaklaşım olduğunu belirtmektedir. Bunun da bir Ermeni kralı olabileceğini belirtir. Bunun dışında yazıtların içeriğinde Persler ve Romalılar'a ait belgelerden ve toplumsal ögelerden bahseder. Yazıtın sahibi kendi görüşlerini de belirttiği bu kitabelerdeki sözlerini kendi halkına yani Ermeni toplumuna vakfetmiş olduğu düşünülmektedir. ${ }^{9}$

Yazıtların devamında şunlar aktarılmaktadır; “...ortaklığımız sona erdi ve (Perslerle birlikte babamıza karşı) savaşmamıza sebep oldu. Ordumuzu ŭ̆runa feda ettiğimiz bu terk edilmiş kale boş kalmamalı. Yeniden karışıklık çıkmasın ve kendi bölgemizin bir kısmı bize karşı ayaklanmasın. ...Her şey çok kötü, siz çektiniz, bunlara sebep olanları tanıyorsunuz'” ${ }^{10}$ Haupt, kitabelerin içeriklerinden hareketle Tigranokerta Kalesi’nden söz edildiğini, Ermeni kralının da bunun kendilerine getirdiği kederi belirtmektedir. ${ }^{11}$

Ayrıca yazar, kitabelerin yazı karakterinden yola çıkarak karşılaştırmalı yöntemle dönem tarihlendirmesi yaparak sonuca varmıştır. Haupt'un vardığı sonuç, kitabenin Ermeni vali Pap'a (369-374) ait olduğu yönündedir. Bu konuda Beysanoğlu'nun V. Minorsky'den aktardığına göre, Haupt'un öne sürdüğü tezini destekler nitelikte şu soruyu yöneltmektedir: "eğer Martyropolis Tigranokerta değilse, kitabenin bulunduğu kaya parçaları şehrin inşası zamanında başka bir yerden getirilmemiş olduğuna göre, burada Pap zamanında hangi meçhul şehir bulunmaktadır?"'12 (F.1).

Yazarın ileri sürdüğü söz konusu iddianın kanıtı durumundaki taş yazıtlardan bir parça bugün hala Silvan Kalesi'nin kuzeybatı sur duvarları üzerinde bulunmaktadır (F.2).

8 Haupt, a.g.e., s. 407-414; Tezcan, a.g.e., s. 29; Beysanoğlu, a.g.e., s. 25.

9 Haupt, a.g.e., s. 407-414; Beysanoğlu, a.g.e., s. 25.

10 Haupt, a.g.e., s. 410-418; Beysanoğlu, a.g.e., s. 99.

11 Beysanoğlu, a.g.e., s. 99; Haupt, a.g.e., s. 410-418.

12 V. Minorsky, “Mayyāfārikīn”, The Encyclopedia of Islam, VI, E. J. Brill, Leiden 1991, s. 197-199, 927-929; Beysanoğlu, a.g.e., s. 99; 349; 

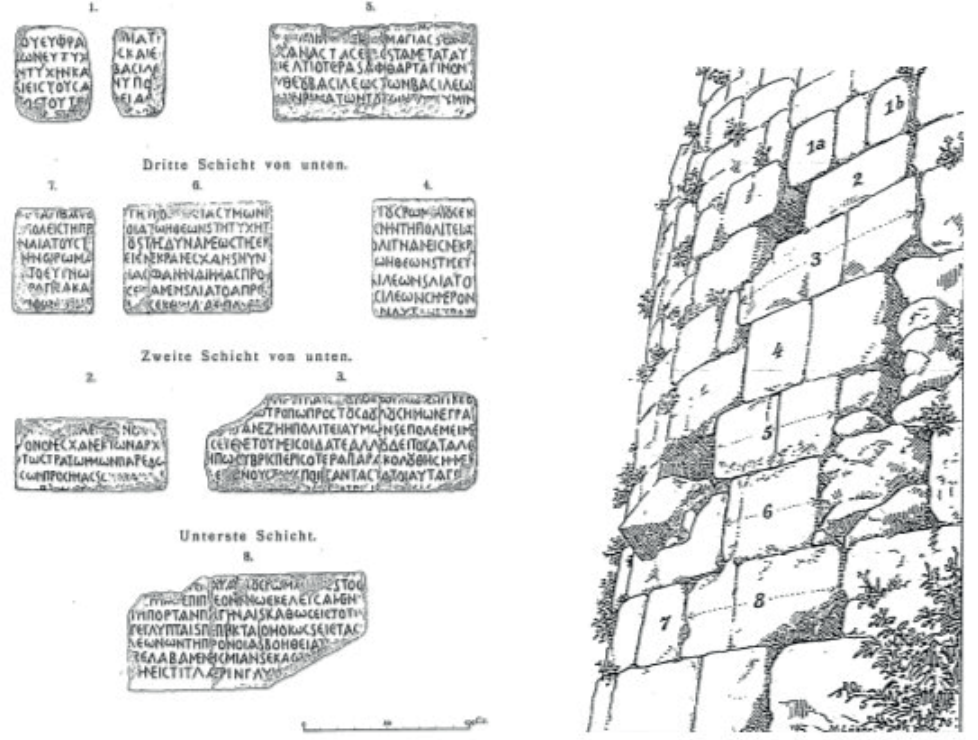

F. 1: Silvan Kalesi sur duvarları üzerinde yer alan yazıtların çizimleri (Haupt, 1988, Çiz.)
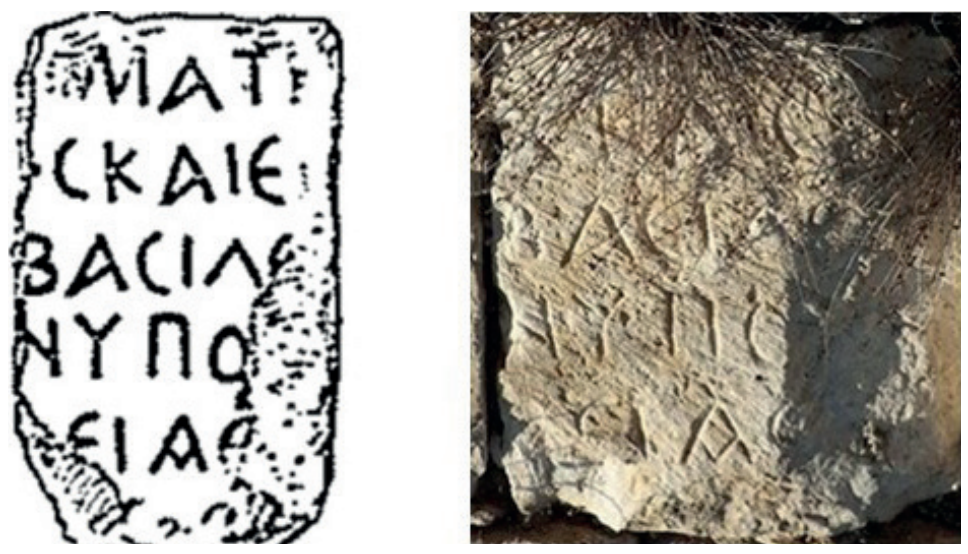

F. 2: Silvan surları üzerinde yer alan ve günümüze ulaşan yazıt parçası (Nejat Satıcı)

Martyropolis kentinin kuruluşu ile ilgili olarak bilinen yaygın diğer bir "kuruluş öyküsü” Ortaçağ İslam kaynaklarında da yer alan Süryânî geleneğine aittir. İbnu'l-Ezrak'ın Martyropolis/ Meyyafarikin'de, Kraliyet Kilisesinde bulunan et-Teş’îs isimli Süryânice el yazmasından Arapçaya çevirdiği metne göre; Martyropolis kenti kurulmadan önce bölgede, Marusa ve babasının sorumlu oldukları coğrafi sahada yerleşim yerlerinin olduğu ve kentin 
(Martyropolis) surları dışında bir mahallenin (köy) varlığından bahsetmektedir. ${ }^{13}$ Dolayısıyla bilgi kaynaklarındaki veriler değerlendirildiğinde Martyropolis'in antik bir şehrin harabeleri üzerinde kurulmuş olduğunu destekler niteliktedir. Yukarıda sunulan görüş ve yaklaşımlar dikkate alındığında Helmuth Von Moltke, ${ }^{14}$ L. Haupt, ${ }^{15}$ J. G. Taylor, ${ }^{16}$ Minoroskiy, ${ }^{17}$ Sinclair ${ }^{18}$ ve diğer araştırmacıların duruma ilişkin fikirleri Martyropolis'in antik bir kentin harabelerinin bulunduğu alanda yeniden inşa edildiği yönündedir.

\section{Kent Organizasyonu}

Ortaçağ İslam kaynakları ve Süryânî kroniğindeki bilgiler göz önüne alındığında Martyropolis 4. yüzyılın sonu 5. yüzyılın başlarında bir Hıristiyan (Bizans kenti) kenti olarak kurulmuştur. ${ }^{19}$ Martyropolis kentinin fiziksel dokusunun ilk oluşumları Bizans döneminde, Mezopotamya piskoposu Marusa b. Lyuta tarafından başlatılmıştır. Oluşturulmak istenen kentsel yerleşim Maipherkat ${ }^{20}$ denilen bölgede, kentin temel unsurları olan kiliseler, kale-sur ve burçlar etrafinda planlanmıştır. Başka bir ifadeyle Bizans kent kurgusunun biçimsel karakterini oluşturan unsurlar, dini yapılar ve bu yapıların etrafını çeviren sur duvarları ve burçlardır.

Martyropolis'in kuruluşu ve mekânsal kent organizasyonu kademeli olarak bazı sistematik adımlar dâhilinde, belirli bir politika çerçevesinde gerçekleştirilmiştir. Şehrin inşa sürecine bakıldığında kentin iki aşamada kurulduğu anlaşılmaktadır. Kentin oluşum süreci ve kurgusu bölgeyi iyi bilen etkin bir kişi olarak gösterilen aynı zamanda bir diplomat ve din adamı olan Marusa tarafından yürütülmektedir. ${ }^{21}$ Marusa, İran ve Bizans sarayları arasında yürüttüğü diplomatik faaliyetlerden dolayı bazı imtiyazlar elde etmişti. ${ }^{22}$ Din adamı, bu imtiyazlara binaen Bizans İmparatoru I. Constantinus'dan kentin kurulması yönünde bazı taleplerde bulunmuştur. $\mathrm{Bu}$ istekler kentsel organizasyonun ilk ön hazırlayıcı adımlarını oluşturmaktadır.

Talep edilen istekler kapsamında Marusa, ilk aşamada, bölgenin yöneticisi olarak doğu sınırında yaşayan Hıristiyan vatandaşların korunması ve barınması için "bir yer” (bir yerleşim alanını) belirlemektedir. Ardından seçilen bu alan üzerine küçük taşlardan yapılmış bir yapı

13 Beysanoğlu, a.g.e., s. 26; İbnu'l-Ezrak, Meyyâfârikîn ve Âmid Târihi (Artuklular Kısmı), Çev. Ahmet Savran, Atatürk Üniversitesi Fen-Edebiyat Fakültesi Yayını, Erzurum, 1992, s. 5; İbn Şeddâd, El-A'lâku'l-Hatîra, C.III/ I, Nrş. Yahya Abbâre, Dimaşk, 1978, s. 261- 63.

14 Moltke, a.g.e., s. 224.

15 Haupt, a.g.e., s. 381-418.

16 J. G Taylor, a.g.e., s. 23-26.

17 Bkz. V. Minorsky, "Mayyāfārikīn”, The Encyclopedia of Islam, VI, E. J. Brill, 1991.

18 T. Sinclair, "The Site Of Tigranocerta", II , REA, 26, 1996 - 1997, s. 51-118.

19 İbnu'l-Ezrak, Târîhu Meyyâfârikîn ve Amid, British Museum, Or.5803, v 7 - 12; İbn Şeddâd, a.g.e., s. 261-64; Albert Gabriel, Voyages Archeologiques Dans La Oriantale, 1940, s. 210-211, 213; Tezcan, a.g.e., s. 33.

20 İbnu'l-Ezrak, a.g.e., Or. 5803, v. 7-12; İbn Şeddâd, a.g.e., s. 261-64; Beysanoğlu, a.g.e., s. 20 - 27.

21 İbn Şeddâd, a.g.e., s. 61-262; R.N. Frye, The Political History of Iran, 1983, s. 142-144; R. Marcus, "The Armenian Life of Marutha of Maipherkat", The Harvard Theological Review, 25, No.1, 1932, s. 47-71; Beysanoğlu, a.g.e., s. 26.

22 Marcus, a.g.e., s. 62-65; Frye, a.g.e., s. 142-144; Beysanoğlu, a.g.e., s. 26 - 27; Tezcan, a.g.e., s. 31-33. 
(kerpiç kemerler) bina ettirmiştir. ${ }^{23}$ Sonrasında meydana getirilen bu yerleşim alanının etrafı “diken ve çalılıklarla” çevreleyerek şehrin fiziki sınırlarını belirlemeye çalışmıştır. Böylece güvenliği sağlanacak alan üzerine, Marusa, “Tepede” büyük bir kilise inşa ettirir. Din adamı, yine "tepede" sağlam olmayan, sur duvarına benzeyen bir duvar yaptırmıştır. Böylece Bizans kent kurgusunu belirleyen ilk somut adımlar da gerçekleştirilmiştir. ${ }^{24}$

Şehrin kurucusu olan din adamı aynı konu bağlamında İran sarayına da çeşitli ziyaretlerde bulunmaktadır. Gerçekleştirdiği ziyaretlerden birini bir barış antlaşması ile sonuçlandırır. ${ }^{25} \mathrm{Bu}$ çerçevede İran hükümdarından bir istekte bulunur. İran topraklarında öldürülen Hıristiyan şehit azizlerin kemiklerini toplamak isteğini İran hükümdarı Şapur'a bildirir. ${ }^{26}$ Zira toplanan bu rölikler kuracağı kentin kilisesi ve inşa edilen kemerlerin aralarına yerleştirmeyi amaçlamaktadır. Böylece kente istenilen kutsallık da atfedilmiş olacaktı. Tüm bu süreç göstermektedir ki, Marusa'nın yürüttüğü politika ve gerçekleştirdiği diplomatik faaliyetler, şehrin kuruluşunu gerek Bizans İmparatoru ve gerekse İran Hükümdarı Şapur tarafından açık bir şekilde desteklenmesini sağlamıştır. Bu girişimlerin ardından Bizans'ın doğu sınırında güvenli bir yerleşim alanının oluşum süreci de olumlu yönde sonuçlandırılmıştır.

Şehrin üzerine kurulacağı coğrafi sahanın belirlenmesinden sonra şehrin fiziki yapısı ve kentin mekânsal örgütlenmesini biçimlendiren mimari unsuların (ikinci aşama) tek tek inşa edilmesine geçilmiştir. Kentsel kurgunun bu ikinci ve önemli aşamasında, Marusa' nın oluşturduğu yerleşim düzenini de içine alacak daha büyük bir toprak sahası üzerine Martyropolis'in mekânsal kent organizasyonu şekillendirilmiştir. Marusa bu aşamada kentin güvenliğinin sağlanması için İmparatorun hamiliğinde Martyropolis Kalesi’nin yapımını başlatmaktadır. Çünkü güvenlik sorunu henüz tam anlamıyla giderilmemişti. Bu amaçla kentin belirlenen noktalarına birer kilise ve burç inşa edilmiştir. Bizans İmparatoru, ekonomik destek sağlamanın yanı sıra çevre bölgelerden Kostantiniye denizine kadar uzanan yerleşim yerlerinden de para toplanmasını ve kentin inşa sürecinin tamamlanmasını istemiştir. ${ }^{27} \mathrm{Bu}$ adım Martyropolis'in kentleşme sürecini hızlandıran faktörlerden bir olmuştur. Genel olarak bakıldığında İmparatorluğun doğu sınırında, Bizans kentleşme pratiğinin işleyiş süreçleri görülmektedir.

Tarihi kaynaklarda yer alan veriler değerlendirildiğinde, Özellikle İbnu'l- Ezrak, Procopious ve İbn Şeddâd'ın verdiği bilgiler doğrultusunda, Silvan (Martyropolis) ilçesinde uzun bir süre saha çalışmasını gerçekleştirdik. Yaptığımız bu arazi çalışması kapsamında, kilise ve burçların Martyropolis (Silvan) kentinin üç noktasına doğu, kuzey ve güney yönünde inşa edildiği belirlenmiştir. A. Gabriel'in çizimlerinden yararlanarak kilise ve burçların üzerine inşa edildiği

23 Beysanoğlu'nun eserinde kerpiç kemerlerin yapıldığı belirtilmektedir. Ancak bizce bu dini nitelikli bir yapı olmalıdır. Şapel veya kilise gibi. Bknz. Şevket Beysanoğlu, Anıtları ve Kitâbeleri ile Diyarbakır Tarihi, Cilt, I, s. 27.

24 İbn Şeddâd, a.g.e., s. 263-264; Marcus, a.g.e., s. 64-65; Beysanoğlu, a.g.e., s. 26;

25 İbn Şeddâd, A.e., s. 263-264; Frye, a.g.e., s. 142-144; Marcus, a.g.e., s. 62-65.

26 A.e., s. 263-264; Albert Gabriel, Şarki Türkiye'de Arkeolojik Geziler, Ankara, 2014, s. 192-195; Beysanoğlu, a.g.e., s. $26-27$.

27 İbn Şeddâd, a.g.e., s. 265; Beysanoğlu, a.g.e., s. 27. 
alanlar işaretlenerek gösterilmiştir (F.3). Buna göre, Bizans İmparatoru'nun izni doğrultusunda ilk olarak, kentin doğu tarafindaki dağa bakan köşede (doğu, kuzeydoğu köşesi), Kral Burcu diğer adıyla Rûmiyye Burcu ve Akabe Kilisesi inşa edilmiştir. ${ }^{28}$ Kalenin bu ilk burcu üç katlı olarak inşa edilmiş, üçüncü katı Akabe Kilisesi olarak yapılandırılmıştır. Kral Burcu'nun konumlandığı bu alan kentin hâkim noktasıdır. Kentin bu bölümü (doğu, kuzeydoğu köşesi) İslami dönemde de kentleşmenin yoğun olduğu bir alan olmuştur. Nitekim bu burca hâkim olanın kente de hâkim olacağı düşüncesinin olduğu görülmektedir. Bu düşünceyle Mervani saray kompleksi bu alan üzerine kurulmuş ve Kral Burcu/Hükümdarlık Burcu Mervani saray kompleksi içerisine dâhil edilmiştir. Bu dönemde (İslami dönemde) burç, yönetim birimi olarak kullanılmıştır. ${ }^{29}$

İmparatorun üçüncü yardımcısı, bugün kuzey sur duvarları üzerinde yer aldığı kabul edilen Rabad Burcu Kapısı (Aşağı Mahalle Kapısı/Boşat Kapısı) ve Yuvarlak Kilise (yuvarlak planlı) ${ }^{30}$ olarak adlandırılan yapıların inşasını üstlenmiştir. ${ }^{31}$

Kentin üçüncü noktasına ise, bugün, Silvan ilçesinin güney yönünde yer aldığını düşündüğümüz Râviyye/Zâviyye Burcu' ${ }^{32}$ (Ali b. Vahap Kapısı Burcu) inşa edilmiştir. Başka bir ifade ile İbnu'l-Ezrak'ın Meyyâfârikîn ve Âmid Târîhi adlı eserinin “Mervani Kürtleri Tarihi”" bölümünü incelediğimizde kentte inşa edilen bu üçüncü burcun bu yönde inşa edilmiş olduğunu öngörmekteyiz. ${ }^{33}$ Ezrak'1n verdiği bilgiye göre burç, yaşadığı çağda (12. yüzyıl) Ali b. Vahab/ Veheb Burcu Kapıs1 ${ }^{34}$ olarak anılmaktadır. Kaynakta belirtildiğine göre Ali b. Vahab/Veheb Burcu'nun yanında, Ali bin Mansur bin Kek’ın bahçesinde, Mervani hükümdarı bir Sanayi Çarşısı (Demirciler Çarşısı) yaptırmıştır. ${ }^{35}$ Yaptığımız saha çalışması ve kaynak araştırmasında, Ortaçağda inşa edilmiş olan bu çarşının, günümüzde halk arasında kendi (Ortaçağ) dönemindeki isimlendirmenin hâla yaygın bir şekilde kullanıldığı anlaşılmıştır. Demirciler Sokağı'nın bulunduğu alanda, Silvan İlçesi'nin (Silvan Kalesi güney yönü) güneyinde, Demirciler Çarşısı olarak adlandırılan bir çarşının varlığını hâla devam ettirdiği tespit edilmiştir. Bu alan yerli halk arasında olduğu gibi resmi kayıtlarda da Demirciler Sokağı olarak tanımlanmıştır. Çarşının 1990 yılına kadar aktif bir şekilde işlerliğini sürdürdügüü, daha sonraki süreçte kentleşme ve güvenlik sorunlarından dolayı eski işleyişini kaybettiği anlaşılmaktadır. Günümüzde ise sadece demir işiyle uğraşan bir dükkânın varlığını koruduğu görülmüştür. Bu da Martyropolis Kalesi’nin üçüncü burcu (Râviyye/Zâviyye Burcu) kentin güneyinde inşa edilmiş olabileceği fikrini vermektedir.

28 İbn Şeddâd, a.g.e., s. 266-67; Gabriel, a.g.e., 2014, s. 192-194; Beysanoğlu, a.g.e., s. 26-27; Süleyman Savc1, Silvan Tarihi, Diyarbakır, 1956, s. 9.

29 İbnu'l- Ezrak, a.g.e., s. 38.

30 Yapının planından dolayı bu isimlendirme yapıldığını düşünmekteyiz.

31 İbn Şeddâd, a.g.e., s. 266; Gabriel, a.g.e., 2014, s. 193-194.

32 Burada Kral Burcu dışındaki diğer iki burcun isimleri Ortaçağ İslam kaynaklarında olduğu şekliyle yazılmıştır. Bizans döneminde bu burçlara verilen bir isim var mıydı, sorusuna şu an için yanıt veremiyoruz. Bu anlamda henüz herhangi bir bilgi kaynağına ulaşılamamıştır.

33 İbnu'l-Ezrak, Mervani Kürtleri Tarihi, Çev. M.E Bozarslan, 1975, s. 159.

34 İbn Şeddâd, a.g.e., s. 266-267; Gabriel, a.g.e., 2014, s. 193.

35 İbnu'l- Ezrak, a.g.e., 1975, s. 159; Beysanoğlu, a.g.e., s. 182. 
Ezrak, ayrıca burç ile aynı dönemde, tepenin yamacında bulunan bir kilisenin inşa edildiği, ${ }^{36}$ kilise yapısının üzerinde, yönü Kudüs’teki Kamâme Kilisesi'ne çevrili olan bir Haç'ın yer aldığı bilgisini vermektedir. Ancak Ezrak, bu yapının 12. yüzyılda (Ezrak’ın yaşadığı çağda) yıkık halde olduğunu bildirmektedir. ${ }^{37}$ Sonuç olarak bu imar faaliyetleri ile birlikte Bizans kentinin fiziksel yapısını meydana getiren bu ikinci aşama da tamamlamış olmaktadır.

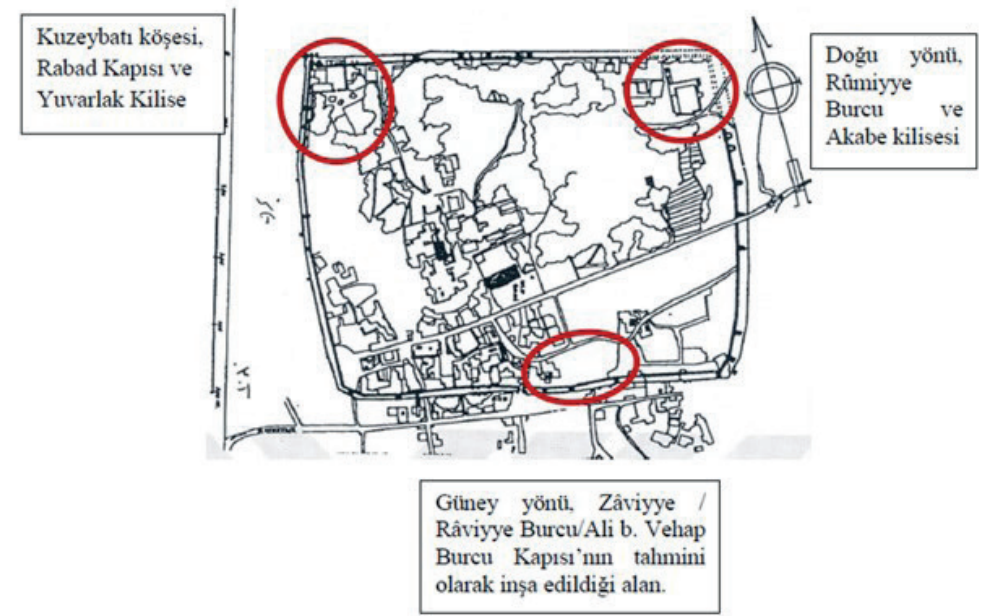

F. 3: Bizans dönemi; Martyropolis kentinde ilk burçlar ve kilise yapılarının inşa edildikleri tahmini alanlar (Gabriel, 2014, Çiz)

Martyropolis Şehri’nin demografik yapısı ağırlıklı olarak Hıristiyan nüfusa sahip olsa da farklı din, mezhep ve etnik kökenlerden halk grupları da bulunmaktaydı. Başka bir ifadeyle Martyropolis'in yerleşim düzeninin şekillenmesinde, dini ve toplumsal yapının dolaylı bir etkisi olduğu söylenebilir. Örneğin, kentte bir Yahudi Sokağı'nın ${ }^{38}$ olduğu ve Müslümanların kente girdikleri sırada yapılan bir anlaşma ile kendilerine bir mahallenin tahsis edildiği bilinmektedir. ${ }^{39}$

Günümüzde, Bizans ve İslam dönemi kent yerleşkesi üzerinde hâla yaşam devam ettiği için sokak ve mahalle düzenlemesi ve altyapı sistemleri hakkında net bir bilgi elde edilememektedir. 1932'de şehri ziyaret eden A. Gabriel modern yapıların karmaşık ağları içinde antik yolların izlerinin artık bulunamadığını söylemektedir. ${ }^{40}$ Bugün Silvan ilçesini (Martyropolis) enine kesen, doğu-batı doğrultusunda uzanan Gazi Caddesi ve dikey yönde kuzey-güney eksenli

36 İbn Şeddâd, a.g.e., s. 266; Gabriel, a.g.e., 2014, s. 193.

37 A.e., s. 266; Gabriel, a.g.e., 2014, s. 193.

38 Söylemez, a.g.e., s. 94.

39 Alican, a.g.e., s. 184-85.

40 Eserin Türkçe çevirisinde antik yolların izinin bulunulduğu, ancak eserin orijinalinde, Fransızca nüshasında antik yollardan günümüzde herhangi bir izin olmadığı bildirilmektedir. Albert Gabriel, Bkz. "Voyages Archeologiques Dans La Oriantale", 1940, s. 211-213. 
Karabehlül Bey Caddesi ve Azizoğlu Caddesi’nin eski sokak/cadde düzeni ile herhangi bir bağı bulunmamaktadır. Bu caddeler, Cumhuriyet dönemi sonrası düzenlenmişlerdir.

\section{Martyropolis Şehir Surları}

Silvan (Martyropolis/Meyyafarikin) ilçesinde 2017 ve 2018 yıllarında gerçekleştirilen alan çalışmasında Bizans dönemi Martyropolis kent surlarına dair bir ize rastlanılmamıştır. Ancak Bizans dönemine ait temel seviyesindeki duvar izlerinin bulunabilmesi için teknik bir çalışmanın yapılması gerekmektedir. Öte yandan şu ana kadar herhangi bir kazı çalışması yapılmadığından dolayı Bizans kent surları hakkındaki bilgiler yazılı metinlere dayanmaktadır.

Şehrin kuruluş aşamasında güvenlik endişesi gerekçesiyle Marusa tarafından inşa edilen ilk surlar (sura benzeyen duvar), sembolik olarak kale-kentin sınırlarını belirlemek için meydana getirilmişti. Sonraki süreçte Bizans İmparatorunun desteğiyle üç noktada burçlar inşa edilmiş ve bunların etrafları çevrelenerek Martyropolis Kalesi'nin ilk çekirdeği oluşturulmuştu. Anlaşıldığı kadarıyla bu ilk sur duvarları çok yükssek olmayan ve yeterince kentin güvenliğini sağlayacak türden korunaklı değillerdi. ${ }^{41}$

Çeşitli zamanlarda Bizans ve Sasani devleti arasında yaşanan siyasi karışıklık Martyropolis kent surlarının güçlendirilmesini gerekli kılmıştır. Bizans imparatorları I. Iustinianos ve I. Anastasius tarafından surlar tahkim ettirilmiştir. Örneğin: I. Iustinianos döneminde kenti çeviren surlar yeniden yapılandırılmış ve güçlendirilmişlerdir. ${ }^{42}$ Bu dönemde askeri bir merkez olarak yapılandırılmaya çalışılan Martyropolis'in güvenlik sorunlarının halledilmeye çalışıldığı görülmektedir. I. Iustinianos dönemi imar faaliyetleri yapılmadan önce surların genel görünümleri ile alakalı olarak sur duvarlarının zayıf ve üzerine tırmanarak çıkılabilecek bir yükseklikte olduğu kaydedilmektedir. ${ }^{43}$ Procopius'un kaydettiği verilere göre, İmparator I. Iustinianos tarafından gerçekleştirilen yeniden yapılandırma kapsamında ilk önce şehir surlarının savunma amaçlı olarak yüksekliğinin iki katına çıkarıldığı bilgisi verilmektedir. ${ }^{44}$ İkinci bir sur duvarının temeli atılmış, bu temel bir önceki sur duvarına dört ayak uzaklıkta ve dört ayak derinlikte düzenlenmiştir. Yapılan surun bir önceki surla aynı teknik özelliklerde inşa edildiği yükssekliğinin ise yaklaşık olarak 6.096 m (uzunluğunun 20 ayak) olduğu anlaşılmaktadır. ${ }^{45}$ Procopious' un kaydından anlaşıldığı kadarıyla kent surları çift sur şeklinde düzenlenmiş, çok daha güçlü bir hale getirilmiştir. Martyropolis kent surlarına ilişkin değerlendirmelerde bulunan A. Gabriel, I. Iustinianos dönemi Dara kent surlarında yapılan restorasyon ve yapılandırma çalışması gibi Martyropolis surlarında da benzer uygulamaların yapılmış olabileceğini söylemektedir ${ }^{46}$ (F.4).

41 Albert Gabriel, a.g.e., 2014, s. 192.

42 Procopius, Of the Buildings of Justinian, İngilizce Çe: Aubrey Stewart, Londra, 2005, s. 76-79; Albert Gabriel, a.g.e., 2014, s. 192.

43 Procopius, a.g.e., s. 76-79, Albert Gabriel, a.g.e., 2014, s. 192.

44 Procopius, a.g.e., s. 76-79; Albert Gabriel, a.g.e., 2014, s. 192; Taylor, a.g.e., s. 24-25; Minorsky, a.g.e., s.197; Ernst Honigmann, Bizans Devletinin Doğu Sınırı, 1971, s. 14-16; Beysanoğlu, a.g.e., s. 27-28.

45 Procopius, a.g.e., s. 76-79; Gabriel, a.g.e., s. 192.

46 Gabriel, a.g.e., s. 192. 


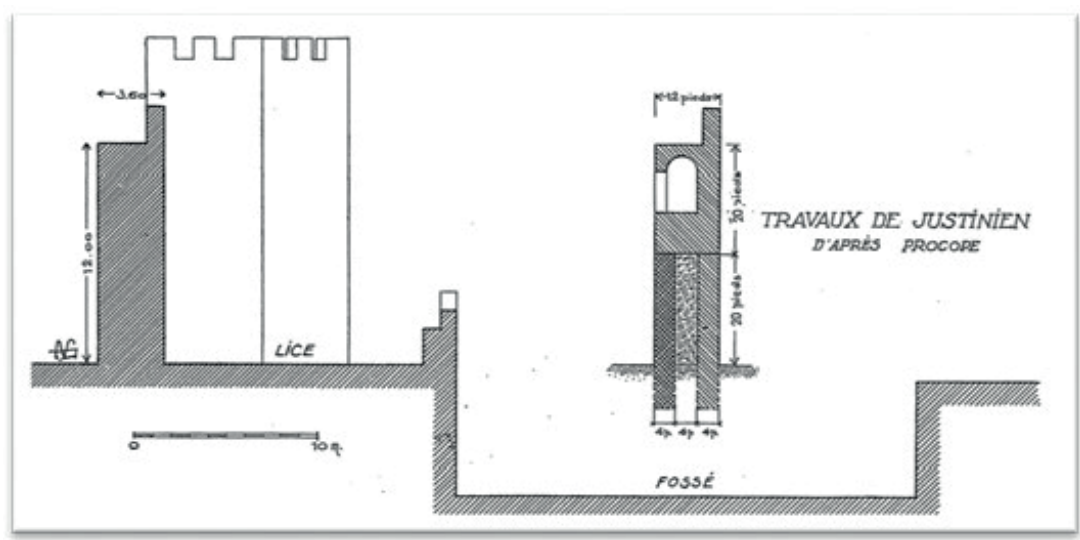

F. 4: Bizans dönemi sur duvarların çizimleri, I. Iustinianos dönemi yapılan onarımları gösteren taslak çizim. (Gabriel, 2014, Çiz.)

İslam döneminde, Meyyafarikin/Martyropolis surlarının birçok kez onarım gördüğü ve kentin savunması kapsamında yeniden yapılandırma ve inşa (kapı ve burç ekleme) çalışmalarının uygulandığı aktarılmaktadır. ${ }^{47} \mathrm{Bu}$ da Bizans dönemi surların büyük çoğunluğunun dönüştüğünü göstermektedir. Özellikle Ortaçağ Kürt devleti Mervaniler döneminde gerçekleştirilen “yeniden inşa ve yapılandırma" çalışmaları sırasında Martyropolis kent surlarının büyük bir bölümünün dönüşüm geçirdiğini ortaya koymaktadır. Kayıtlı metinlerde yer alan bilgilere göre Mervani emiri Mümehhidüddüvle döneminde ve emir Nasruddevle zamanında iç ve dış sur üzerindeki burç ve kapıların yıkılıp yeniden inşa edildiği bilgisini vermektedir. ${ }^{48}$ Ancak genel olarak I. Iustinianos döneminde şekillendirilen sur duvarlarının ana sınır hattının İslam döneminde de korunduğu kabul edilmektedir. Sonuç olarak Bizans dönemi; Martyropolis surlarının ana yapısının 5. ve 7. yüzyılın ikinci yarısına kadar ki süreçte şekillendiği, Müslümanlar döneminde de bu ana sur hattının korunduğu, kalenin yeni savunma unsurları ile yeniden tahkim edildiği anlaşılmaktadır.

A. Gabriel yaptığı incelemeler sonucunda Silvan kalesinin fiziki sınırlarını şu şekilde tanımlamıştır. Kareye yakın bir alan üzerine kurulmuş, doğuda ve batıda 600 m., kuzey ve güney yönlerde 500 m., toplam da 2200 uzunluğunda olmalıdır. ${ }^{49}$ Yazar, Ortaçağ İslam kaynaklarına dayanarak kale üzerinde sekiz kapı göstermiştir. Ancak Bizans döneminde, kentin kuzey, güney, doğu ve batı yönlerine açılan birer kapının var olduğunu düşünmekteyiz. Bu kapılar: kent planının ana aksına denk gelecek şekilde kuzey-güney, doğu-batı eksenli olmalıdır. (F.5).

47 İbnu'l-Ezrak, a.g.e., 1975, s. 99, 155.

48 İbnu'l-Ezrak, a.g.e., 1975, s. 99, 155; Gabriel, a.g.e., s. 192-194.

49 Gabriel, a.g.e., s. 187. 


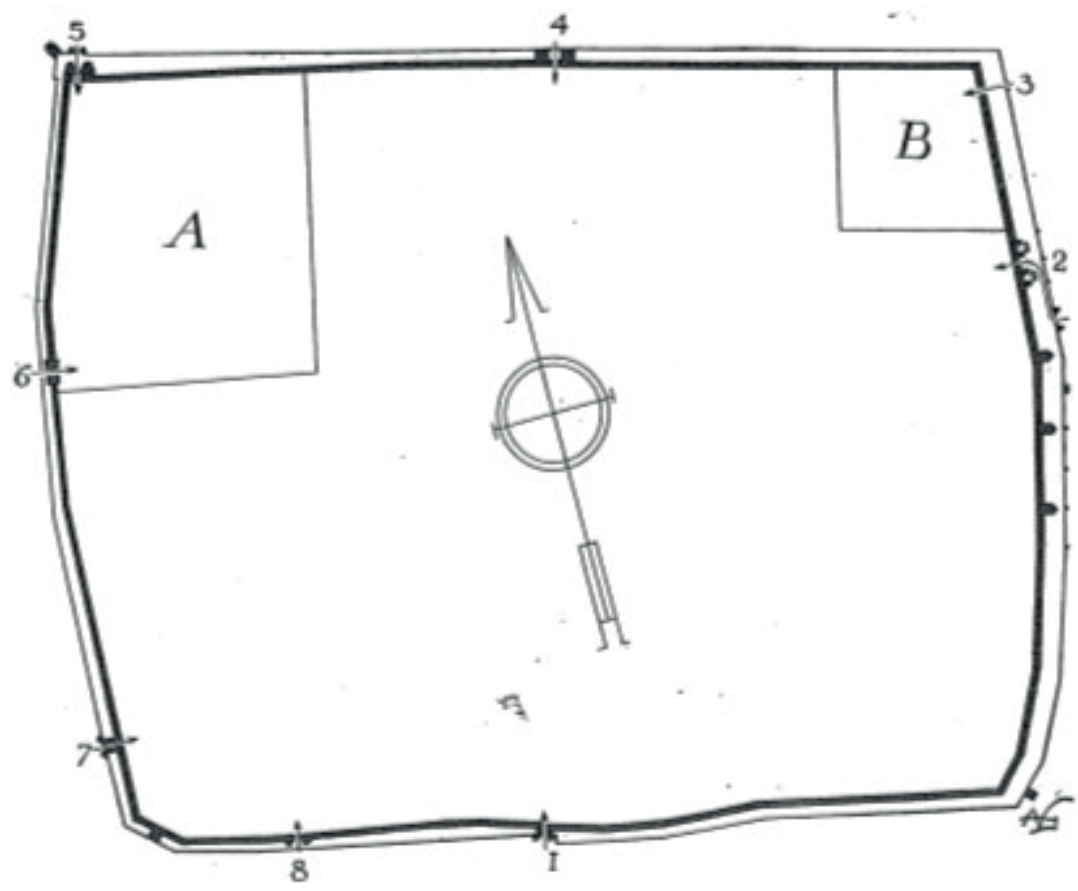

F. 5: Meyyafarikin/Silvan Kalesi ve üzerinde yer alan kapılar (Gabriel, 2014, Çiz.)

\section{Kentteki Kiliseler}

Martyropolis kentindeki kilise yapılarına ilişkin bilgi kaynakları ve görsel malzemeler mevcutken, bu yapılardan günümüze ulaşan mimari kalıntılar ise yok edecek kadar azdır. ${ }^{50}$ Kentin Müslüman idarecilerin eline geçmesinden sonra şehirdeki dini (kiliseler) mabetlerin kendi cemaatlerine hizmet vermeye devam ettikleri anlaşılmakla birlikte bir süre sonra yapıların sayılarında bir azalma olduğu öngörülmektedir. 21. yüzyılın ortalarına gelindiğinde ise bu yapıların çoğuna ait mimari kalıntıların yok olduğu tespit edilmiştir.

Martyropolis'in kentleşme sürecinin ilk yıllarında, kentte inşa edilen dört adet kilisenin varlığından bahsedilmektedir. Kentteki ilk kiliselerden biri olarak kabul edilen, Ezrak'ın kaydında "Kraliyet Kilisesi"”, , Şeddâd'ın ise "Büyük Kilise" olarak tanımladığı yapı İmparator'un emri ile Marusa tarafindan inşa edilmişti. ${ }^{52}$ Din adamı tarafindan inşa süreci organize edilen bu "Büyük Kilise", ${ }^{53}$ aynı zamanda Martyropolis kentinin sembolik yapısı olmaktaydı. Marusa'nın Mezopotamya ve İran topraklarında ölen (Şehit edilen) Hıristiyan dindaşların kemiklerini

50 Max Van Berchem- Josef Strzygowsk1, Amida, Carl Winter's Universitaetsbuchhandlung, Paris, 1910, s. 365-367; Gertrude Bell, Newcastle University Archives; ErnestChantere, http:/gallica.bnf.fr/ark:/12148/btv1b8451594j/ f42.planchecontact.r $=$ medja $\% 20$ farkin? $r k=21459 ; 2$

51 İbnu'l-Ezrak, a.g.e., s. 29.

52 İbn Şeddâd, a.g.e., s. 266.

53 A.e., s. 266. 
yerleştirdiği bu yapı, Aziz Petrus ve Aziz Pavlos'a ithaf edilmiştir. ${ }^{54}$ Martyropolis kentinin bu sembolik kilisesinin kalıntıları 20. yüzyıla kadar geldiği bazı araştırmacılar tarafından kabul görmektedir. ${ }^{55}$ Ancak Ortaçağ kaynakları ve yakın dönemde kenti gezen seyyahlar ve araştırmacıların aktardığı veriler incelendiğinde bu konuda çok karmaşık bir bilgi yı̆̆ının meydana geldiğini söylemek gerekir. Dolayısıyla bu durum kentteki yapıların tarihlendirilmesi konusunda bir problem yaratmaktadır.

19. ve 20. yüzyılda Silvan'1 gezen Ernest Chantere, Gertrude Bell, Süleyman Savcı, J. G. Taylor ve O. P. Allen ve Max van Berchem - Jozef Strzygowski gibi araştırmacıların bilgi kaynakları ve görsel materyallerinden yararlanılarak Martyropolis'de bulunan kiliselerin mimari unsurlarını görmek mümkündür ( F. 6-11 ).

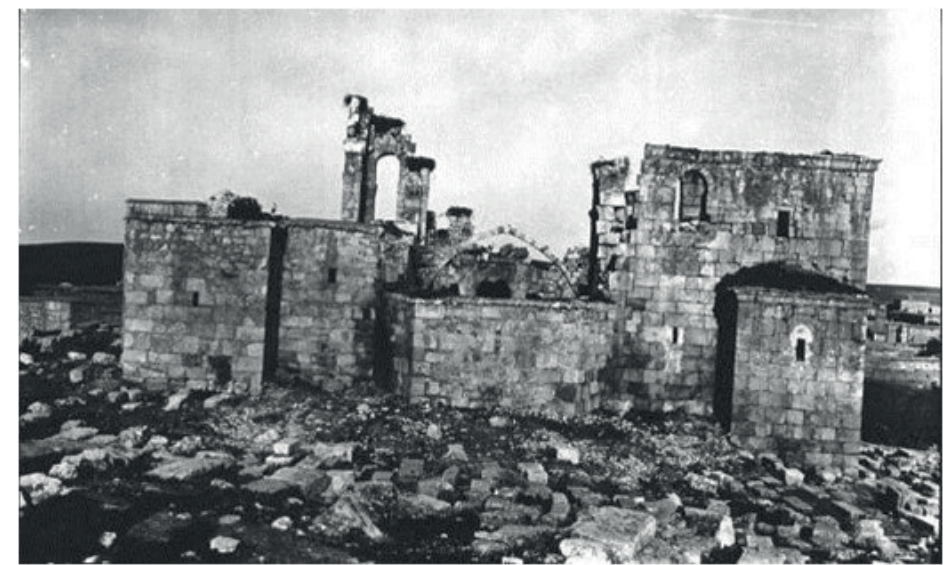

F. 6: Martyropolis kilisesi, dış cepheden görünüş ( Bell, 1911)

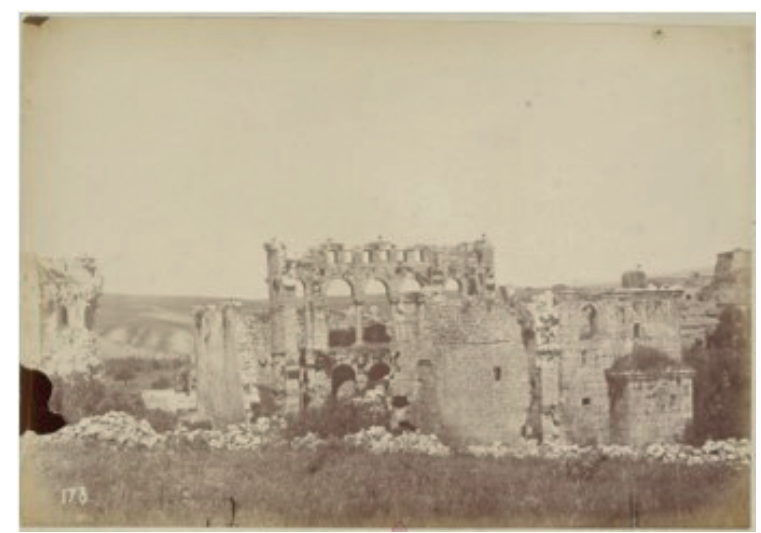

F. 7: Martyropolis kilisesi, (Chantere, 1881)

54 Söylemez, a.g.e., s. 94-95.

55 O. P, Allen, "Proceedings at Bostan and Cambridge May. 22d. 1867", Journal Of American Oriemal Society, Vol: 9 1868-1871, XIII-XVIII; Taylor, a.g.e., s. 24; Gertrude Bell, Newcastle University Archives. 


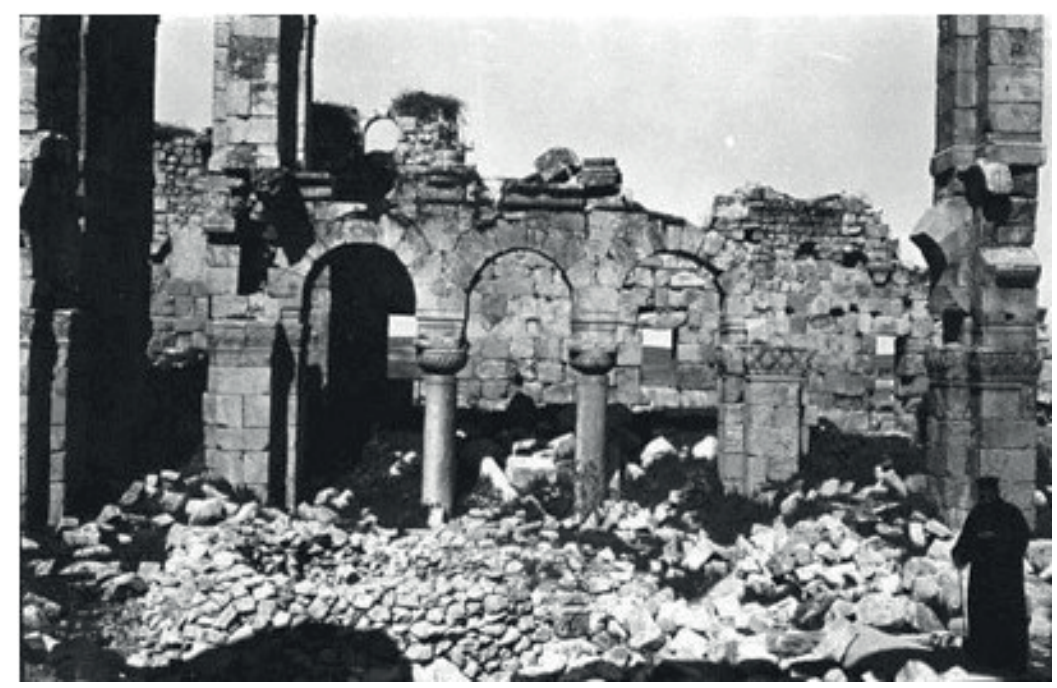

F. 8: Silvan/Martyropolis kenti, kilisenin iç mekân görünümü (Bell, 1911)
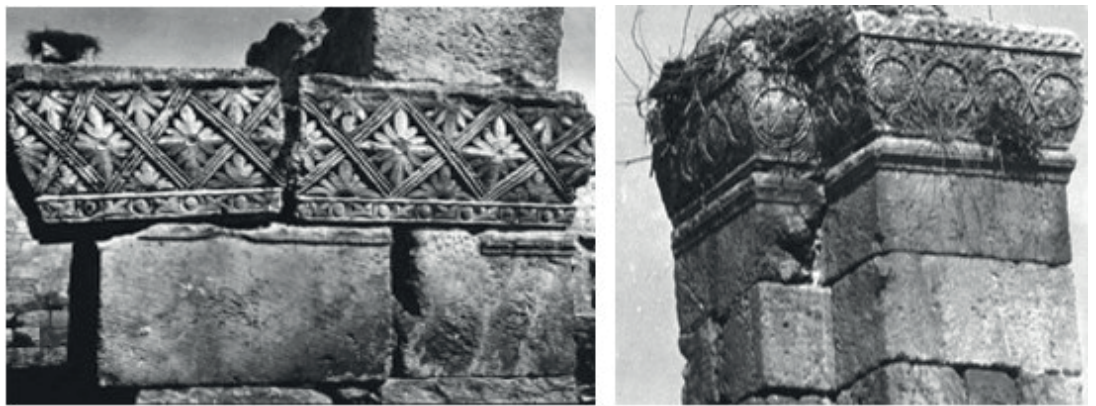

F. 9: Silvan/Martyropolis kenti, kilisenin iç mekân süsleme unsurları ( Bell, 1911)

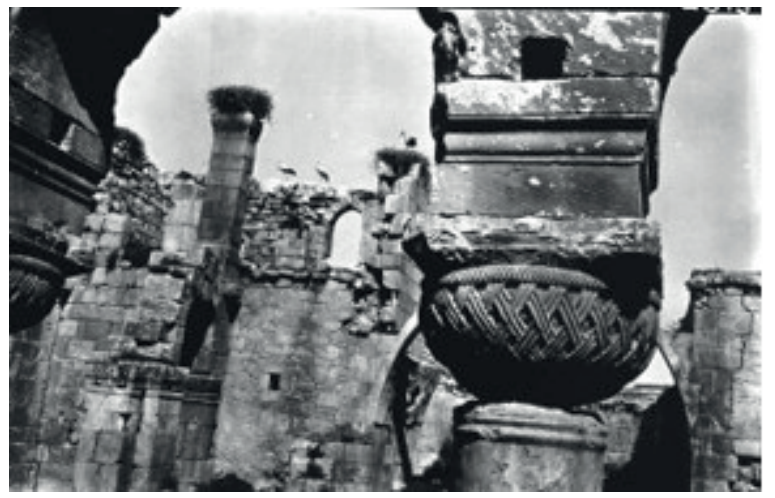

F. 10: Silvan/Martyropolis kenti, sepet tarzı süsleme başlıkları (Bell, 1911) 


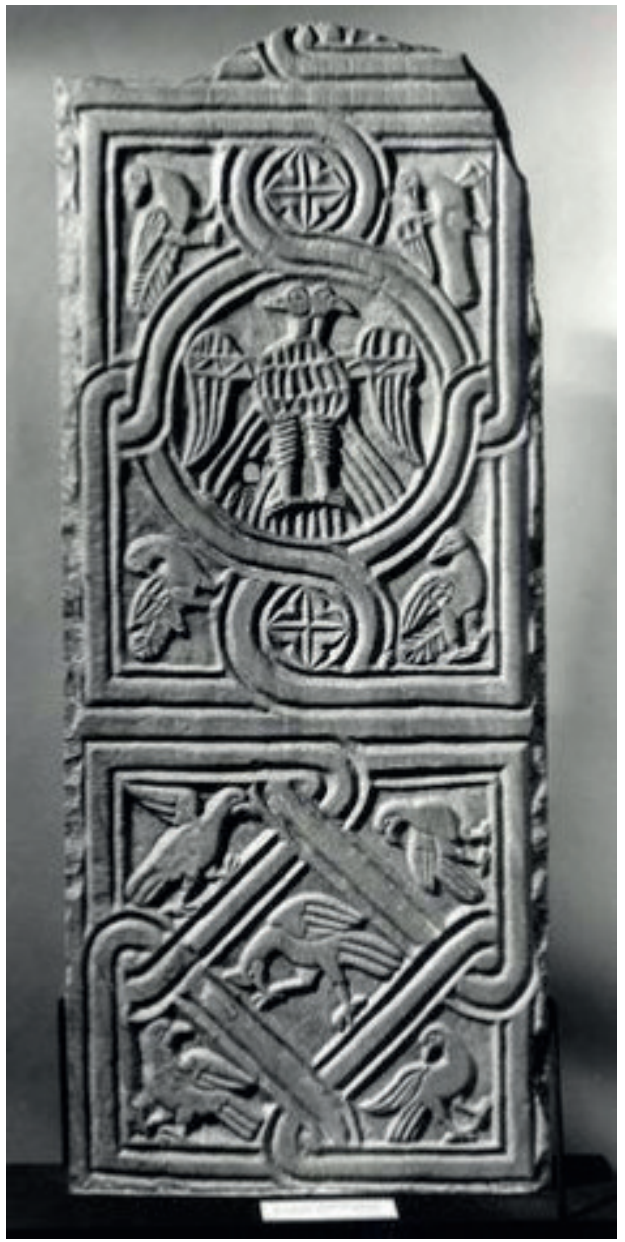

F. 11: Martyropolis Kilisesi, mermer levha parçası (Berchem-Strzygowski,1910)

\section{Sonuç}

Bu çalışmada, 5.-7. yüzyıllar arasında Erken Bizans döneminde Güneydoğu bölgesinde gelişen şehirleşme politikası ele alınmıştır. Bu dönemdeki kentleşme süreci bölgede var olan antik kentlerin Hıristiyan kentine dönüşümü şeklinde olmuştur. Martyropolis ve Dara bu şekilde kurulmuş önemli Bizans şehirleridir.

Çalışmada, Bizans devletinin doğu sınırında kurulan Martyropolis kent yerleşimi üzerine genel bir değerlendirme sunulmuştur. Bir sanat tarihçisi olarak Martyropolis’in kentsel yapılanma sürecinin dini, politik, tarihi ve demografik açıdan nasıl şekillendiği sorgulanmıştır. Dönem kaynakları: Ortaçağ İslam kaynakları, Bizans dönemi yazılı metinler, Süryâni kronikleri, ve mimari bulgular dikkate alınarak Martyropolis'in yapısal ve dokusal bağlarının çözümlenmesi 
yapılmıştır. Böylece Doğu/ Güneydoğu bölgesinde, Bizans dönemi kentleşme ve kent planlamacılığını anlamaya yönelik taslak bir çalışma oluşturulmuştur.

Kentin inşa edilme sürecinde bazı belirleyici unsurlar ön plana çıkmaktadır. Bu unsurlar; Bizans İmparatorluğunun Hıristiyanlığı resmi din olarak kabul etmesiyle birlikte bölgedeki Hıristiyan dindaşlarına güvenli bir yerleşim alanı oluşturma düşüncesi, devletin merkezileşme politikası ve doğu sınırın güvenliğini sağlama isteği şeklinde sıralanabilir.

Hıristiyan kentin inşası ve gelişim sürecinde Marusa'nın yürüttüğü diplomatik ve dini faaliyetler şehrin kuruluş sürecini başlatmaktadır. Bizans imparatorun mali desteği ile inşa edilen kilise ve burçlar kentin ilk mekânsal örgütlenmesinin plan şemasını ortaya çıkarmaktadır. Özellikle Martyropolis Kalesi’nin inşası kentin fiziki sınırlarını görünür kılmıştır. İmparator I. Iustinianos döneminde, kent askeri merkez olarak yapılandırılmıştır. Kent savunması güçlendirilerek güvenlik sorunu halledilmiştir.

Martyropolis kenti ile ilgili önemli sorunlardan biri kentin mekânsal örgütlenmesi sürecinde, inşa edilen ilk yapıların kentin hangi noktalarına inşa edildiklerinin tespit edilme sorunsalıydı. Tarihi metinlerde yer alan veriler ve gerçekleştirilen arazi çalışması bu noktada sorunun çözümüne yönelik bir fikir ortaya koymamıza firsat vermiştir. Böylece Martyropolis kentinin yerleşim dokusu ve mimarisi üzerine bazı tespitlerde bulunmak mümkün olmuştur. İlk olarak kentteki yapıların yerleri/ konumları belirlenmesi gibi sorunlar ortaya konulmuş ve çözüm önerileri sunulmuştur. Örneğin, mekânsal örgütlenmenin ilk örnekleri olan kilise ve burçlar; kentin belirlenen üç noktasına inşa edilerek planlandığı anlaşılmıştır. Bunlar, doğu, güney ve kuzeybatı köşesi yönünde olmaktadır.

Tipik bir Bizans kent örneğini gösteren Martyropolis'in şehirleşme süreci sistematik bir plan dâhilinde gerçekleştirildiği söylenebilir. 7. yüzyılın ortalarına kadar uzanan bu kentleşme süreci Müslüman ordularının El-Cezire bölgesini alması ile son bulmuştur.

\footnotetext{
Hakem Değerlendirmesi: Dış bağımsız.

Çıkar Çatışması: Yazar çıkar çatışması bildirmemiştir.

Finansal Destek: Yazar bu çalışma için finansal destek almadığını beyan etmiştir.

Peer-review: Externally peer-reviewed.

Conflict of Interest: The author has no conflict of interest to declare.

Grant Support: The author declared that this study has received no financial support.
} 


\section{Kaynakça/References}

Alican, Mustafa, Bir Ortaçağ Kenti Olarak Meyyafarikin, Yayınlanmış Doktora Tezi, Ege Üniversitesi, Sosyal Bilimler Ensitüsü, 2010.

Allen, O. P., "Proceedings at Bostan and Cambridge May. 22d. 1867”, Journal Of American Oriemal Society, Vol: 9 1868-1871, XII-XVIII.

Berchem, M. Van- Strzygowsk1, Josef, Amida, Carl Winter's Universitaetsbuchhandlung, Paris, 1910.

Beysanoğlu, Şevket, Anıtları ve Kitâbeleri ile Diyarbakır Tarihi, Kültür Ve Sanat Yayınları, Cilt: I-II, Ankara, 1996.

Gabriel, Albert, Şarki Türkiye'de Arkeolojik Geziler, Çev. İdil Çetin, Sözkesen Matbası, Ankara, 2014.

Gabriel, Albert, Voyages Archeologiques Dans La Oriantale, Paris, 1-2 cilt, 1940.

Honigmann, Ernst, Bizans Devletinin Doğu Sınırı, Çev. Fikret Işıltan, İstanbul Üniversitesi Edebiyat Fakültesi, İstanbul, 1970.

İbn Şeddâd El-A'lâku'l-Hatîra, III/ I, Nrş. Yahya Abbâre, Dımaşk, 1978.

İbn-ül Ezrak, İbnu'l-Ezrak, Târîhu Meyyâfârikîn ve Amid, British Museum, Or. 5803-Or. 6310.

İbn-ül Ezrak, Meyyâfârikîn ve Âmid Târîhi ( Artuklular Kısmı ), Çev. Ahmet Savran, Atatürk Üniversitesi, Yay., Erzurum, 1992.

İbn-ül Ezrak, Mervani Kürtleri Tarihi, Çev. M. E Bozarslan, Koral Yayınları, 1975.

Lehmann, Haupt- Carl, Friedrich, Armenien Einst Und Jetzt, C. I, George Olms Verlag (Tıpkı Basımı), Berlin, 1988

Minorsky, Vladimir, "Mayyāfărikīn” The Encyclopedia of Islam, VI, E. J. Brill, 1991.

Procopius, Of the Buildings of Justinian, İngilizce Çev: Aubrey Stewart, Londra, 2005.

Ralph, Marcus, "The Armenian Life of Marutha of Maipherkat", The Harvard Theoloji Review, 25, No.1, 1932, s. 47-71.

R. Nelson, Frye, "The Political History of Iran Under The Sasanians" CHI, April 29, v. 3, 1983, s. 115-180.

Ronald, Syme, "Tigranacerta. A Problem Misconceived", Armies and Frontiers in Roman and Byzantine Anatolia, Proceedings of a colloquium held at University College, Swansea, in April 1981, ed. Stephen Mitchell, 1983, s. 61-70.

Savc1, Süleyman, Silvan Tarihi, Diyarbakır Matbaası, Diyarbakır, 1956.

Sinclair, T. Allan, “The Site Of Tigranocerta II”, REA, 26, 1996-1997, s. 51-118.

Söylemez, M. Mehmet, "Meyyâfârikîn (Silvan) Üzerine Notlar”, İslam Şehirleri, Düşün Yayınc1lık, İstanbul, 2011. Süryani Mihail Süryani Mihail Vekayinâmesi, II, yayınlanmamış Türkçe çev. H.

Andreasyan, TTK Kitaplı̆̆ 1 , Ankara, 1944.

Taylor, J. George, "Travels in Kurdistan, with Notices of the Sources of the Eastern and Western Tigris, and Ancient Ruins in Their Neighbourhood", Journal of the Royal Geographical Society of London, Vol. 35, 1865, s. 21-25.

Tezcan, Mehmet, “Tigranakerta İle Silvan/Mayperkat'ın Birleştirilmesi Ve Silvan'nın Durumu”, I. Uluslararası Silvan Sempozyumu, Mardin Artukulu Üniversitesi Yayınları, Mardin, 2008, s. 29-41.

V. Moltke, Helmuth, Türkiye'deki Durum ve Olaylar Üzerine Mektuplar, Çev. Hayrullah Örs, Türk Tarih Kurumu, Ankara, 1960. 